\title{
DANOS CAUSADOS POR Nezara viridula (LINNAEUS, 1758) E Piezodorus guildinii (WESTWOOD, 1837) (HEMIPTERA: PENTATOMIDAE) EM MAÇÃS DE ALGODOEIRO (Gossypium hyrsutum L.)
}

\author{
José Francisco Alves Cruz Junior
}

Dissertação apresentada à Escola Superior de Agricultura “Luiz de Queiroz”, Universidade de São Paulo, para obtenção do título de Mestre em Ciências, Área de Concentração: Entomologia.

P I R A C I C A B A

Estado de São Paulo - Brasil

Fevereiro - 2004 


\title{
DANOS CAUSADOS POR Nezara viridula (LINNAEUS, 1758) E Piezodorus guildinii (WESTWOOD, 1837) (HEMIPTERA: PENTATOMIDAE) EM MAÇÃS DE ALGODOEIRO (Gossypium hyrsutum L.)
}

\author{
José Francisco Alves Cruz Junior \\ Engenheiro Agrônomo
}

Orientador: Prof. Dr. OCTÁVIO NAKANO

Dissertação apresentada à Escola Superior de Agricultura “Luiz de Queiroz”, Universidade de São Paulo, para obtenção do título de Mestre em Ciências, Área de Concentração: Entomologia.

P I R A C I C A B A

Estado de São Paulo - Brasil

Fevereiro - 2004 


\title{
Dados Internacionais de Catalogação na Publicação (CIP) \\ DIVISÃO DE BIBLIOTECA E DOCUMENTAÇÃO - ESALQ/USP
}

\author{
Cruz Junior, José Francisco Alves \\ Danos causados por Nezara viridula (Linnaeus, 1758) e Piezodorus guildinii \\ (Westwood, 1837) (Hemiptera : Pentatomidae) em maçãs de algodoeiro (Gossypium \\ hyrsutum L.) / José Francisco Alves Cruz Junior. - - Piracicaba, 2004. \\ $41 \mathrm{p}$. \\ Dissertação (mestrado) - - Escola Superior de Agricultura Luiz de Queiroz, 2004. \\ Bibliografia.
}

1. Algodão 2. Biologia animal 3. Ecofisiologia vegetal 4. Fitossanidade 5. Percevejo 6

Pragas de plantas 7. Soja I. Título

CDD 633.51

"Permitida a cópia total ou parcial deste documento, desde que citada a fonte - O autor" 
Dedico aos meus pais, Francisco e Zaida, pelo apoio e confiança; aos meus irmãos Eduardo (Carmem), Cristina (Ortega) e Cláudia (Aldo), pela força e auxílio nos momentos mais difíceis; a todos que moram na casa da esquina da Governador Pedro de Toledo com a Joaquim André: minha avó Matilde, minhas tias Edelzia, Bernadete e Tereza, e meu tio José Heraldo, por tudo o que fizeram à mim e ao meu filho.

OfEReÇO ao meu filho, Pedro Henrique, que apesar do destino insistir em manter-nos distantes, estamos sempre unidos de coração. 


\section{AGRADECIMENTOS}

A Escola Superior de Agricultura "Luiz de Queiroz" (ESALQ/USP), pela oportunidade concedida para a realização deste trabalho.

A Coordenação de Aperfeiçoamento de Pessoal de Nível Superior (CAPES), pela concessão da bolsa de estudos.

Ao Prof. Dr. Octávio Nakano, pela amizade, apoio e orientação.

A todos os professores do Setor de Entomologia, pelos ensinamentos recebidos.

A Deltapine, na pessoa do Dr. Marcos Yamamoto, pelo suporte financeiro a esta pesquisa, bem como ao pesquisador Edvaldo Cia, do Instituto Agronômico de Campinas (IAC), pelas análises laboratoriais.

Ao Dr. Tsuioshi Yamada, Diretor do Instituto Potassa, pela liberação da área para a realização deste trabalho.

Aos colegas do Programa de Pós-Graduação em Entomologia, especialmente, Luciano Pacelli, Fabiana Romano, Uemerson Cunha, José Francisco Garcia, Simone Prado, Karina Takahashi e Edmilson Silva, amigos em todos os momentos.

A turma do "Esquadrão Veneno", pelo harmonioso convívio, em especial ao Mitsubishi, pela prestatividade durante a execução do trabalho.

A Augusto Florim, pelo apoio e inestimável amizade.

A todos que contribuíram de alguma forma, manifesto os meus mais sinceros agradecimentos. 


\section{SUMÁRIO}

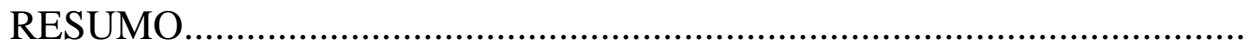

Página

vii

SUMMARY

viii

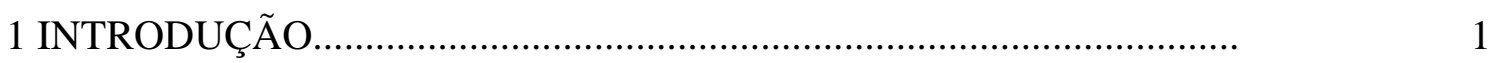

2 REVISÃO DE LITERATURA...............................................................

2.1 Aspectos gerais....................................................................

2.1.1 Botânica e descrição........................................................................

2.2 Aspectos bioecológicos de Nezara viridula e Piezodorus

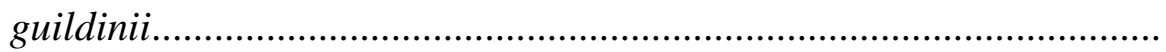

2.3 Danos causados em maçãs de algodoeiro por percevejos migrantes de lavouras de soja.

2.4 Criação de percevejos (Pentatomidae) em laboratório.

3 MATERIAL E MÉTODOS................................................................

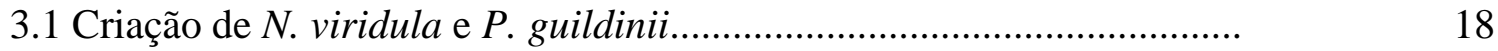

3.2 Influência de $N$. viridula e $P$. guildinii na queda de maçãs..................... 
3.3 Efeito do ataque de $N$. viridula e P. guildinii, nas características tecnológicas da fibra, fio e componentes de produção do algodoeiro...

3.4 Colheita e amostras para análise......................................................

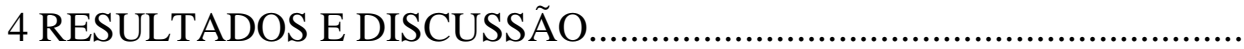

4.1 Influência de $N$. viridula e $P$. guildinii na queda de maçãs

4.2 Danos causados por $N$. viridula e $P$. guildinii, nas características tecnológicas da fibra e do fio do algodoeiro.......

4.2.1 Efeito das espécies em relação aos danos ocorridos nas características componentes de produção (peso de capulho, peso de 100 sementes e porcentagem de fibra)...........................................

4.2.2 Efeito das espécies e da densidade de infestação nas características tecnológicas da fibra e do fio.........................................................

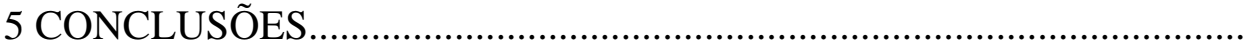

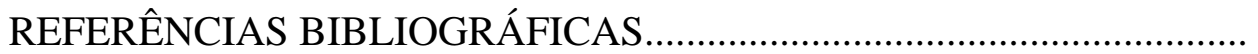




\title{
DANOS CAUSADOS POR Nezara viridula (LINNAEUS, 1758) E Piezodorus guildinii (WESTWOOD, 1837) (HEMIPTERA: PENTATOMIDAE) EM MAÇÃS DE ALGODOEIRO (Gossypium hyrsutum L.)
}

\author{
Autor: JOSÉ FRANCISCO ALVES CRUZ JUNIOR \\ Orientador: Prof. Dr. OCTÁVIO NAKANO
}

\section{RESUMO}

Na região Centro-Oeste do Brasil, o aparecimento de percevejos migrantes da cultura da soja como Nezara viridula (Linnaeus, 1758) e Piezodorus guildinii (Westood,1873), após o processo de colheita, em lavouras de algodão, tem aumentado o interesse dos produtores em relação ao seu controle. Este trabalho teve o objetivo de verificar os tipos de danos que podem ser causados pelos percevejos $N$. viridula e $P$. guildinii nas maçãs e nas fibras do algodoeiro em três fases de desenvolvimento: até 10 dias após a florada, até 20 dias após a florada e até 30 dias após a florada. Para tanto, foram realizadas coletas na região Piracicaba, SP, além da criação em laboratório das duas espécies de pentatomídeos citadas. Os resultados obtidos evidenciaram as injúrias causadas às maçãs (externas, internas e também às fibras) por meio das sucessivas picadas dos percevejos, e permitem concluir que tanto $N$. viridula como $P$. guildinii causam queda significativa de maçãs até 10 dias após a florada e que independente da densidade de infestação, provocam danos nas características de produção e tecnológicas da fibra e do fio do algodoeiro, tendo como conseqüência não só a perda de produtividade como também da qualidade da fibra destinada à indústria. 


\title{
DAMAGE BY Nezara viridula (LINNAEUS, 1758) AND Piezodorus guildinii (WESTWOOD, 1837) (HEMIPTERA: PENTATOMIDAE) IN COTTON BOLLS (Gossypium hyrsutum L.)
}

\author{
Author: JOSÉ FRANCISCO ALVES CRUZ JUNIOR \\ Adviser: Prof. Dr. OCTÁVIO NAKANO
}

SUMMARY

The occurrence of migrant bugs from soybean e.g. Nezara viridula (Linnaeus, 1758) and Piezodorus guildinii (Westood, 1873), in the Centro-Oeste region of Brazil, soon after harvest in cotton farms has increased the farmers interest about tatics to control these pests. This work was carried out to verify the damage that $N$. viridula and P. guildinii cause in bolls and fiber at three developmental stages: until 10, 20 and 30 days after flowering. So, samples were taken at Piracicaba, State of São Paulo, Brazil, and a laboratory rearing of these two pentatomid species was set up. The results showed the damages to the bolls (external, internal and fibers) by sucessive sting bites and lead to the conclusion that $N$. viridula and P. guildinii cause significantly boll drop until 10 days after flowering and without relation with infestation density they damage the technological and production characteristics of cotton fiber and strings, therefore reducing yield and also the fiber industrial quality. 


\section{INTRODUÇÃO}

O algodoeiro, em 2002, foi cultivado em cerca de 81 países, liderados pela China, EUA, Índia, entre outros (Agrianual, 2003). Por sua grande tolerância à seca, a cultura do algodoeiro constitui-se em uma das poucas opções para cultivo em regiões semi-áridas, podendo fixar o homem ao campo, gerar emprego e renda no meio rural e urbano. É, portanto, atividade de grande importância social e econômica.

No Brasil, a cotonicultura consolidou sua recuperação, em termos de produção e até mesmo de inserção nos mercados internacionais, em 2001. Neste ano, depois de chegar a ser um dos maiores importadores mundiais da fibra, o Brasil voltou a exportar volume significativo, superando a marca de 160 mil toneladas de pluma. Esta recuperação deveu-se em grande parte à transformação tecnológica do sistema produtivo da cultura algodoeira e da alta qualidade da fibra, aliada a um dos menores custos de produção do mundo (Agrianual, 2002).

Esta mudança no modelo produtivo do algodão, requerendo alta tecnologia em grandes áreas mecanizáveis, fez com que a lavoura expandisse para novas áreas como Maranhão, na região de Barreiras no cerrado baiano e no Mato Grosso, que se tornou o maior produtor nacional.

A planta de algodão é conhecida mundialmente como uma das mais sujeitas ao ataque de pragas, muitas delas nocivas à cultura. $\mathrm{O}$ algodoeiro atrai e hospeda um complexo significativo de insetos e ácaros, os quais atacam raízes, caules, folhas, botões

florais, maçãs e capulhos. Os danos provocados pelas pragas podem reduzir a produtividade, como também afetar certas características das sementes e da fibra, depreciando-as para a utilização comercial (Santos, 1999). 
A migração da cultura para novas áreas e a utilização de variedades tolerantes ao Mosaico Ribeirão Bonito (virose conhecida como Doença Azul, transmitida pelo pulgão Aphis gossypii), como a Delta Opal, causaram redução na aplicação de inseticidas.

Nos sistemas de produção agrícola, o algodoeiro permanece por um período vegetativo maior que o das outras culturas, como por exemplo, a soja e o milho. Ao final do ciclo da soja, e principalmente após a colheita da mesma, poderá ocorrer uma migração de percevejos desta cultura para a lavoura de algodão, principalmente nas variedades de ciclo tardio (150 a 180 dias), que se encontram em fase final de florada ou também nas variedades que são menos pulverizadas. Estes percevejos migrantes poderão ocasionar danos aos botões florais, como também às maçãs em fase de enchimento (Santos, 1999).

Nesse sentido, o objetivo desse trabalho foi estudar os tipos de danos que podem ser ocasionados devido a ação dos percevejos Nezara viridula e Piezodorus guildinii em maçãs de algodoeiro. 


\section{REVISÃO DE LITERATURA}

\subsection{Aspectos gerais}

As primeiras referências sobre o algodoeiro datam de muitos séculos antes de Cristo. Nas Américas, há evidências de que civilizações Incas utilizavam para o artesanato têxtil, em virtude dos vestígios milenares encontrados no Peru. No Brasil, à época do descobrimento, os indígenas já cultivavam o algodoeiro, utilizando a fibra na confecção de tecidos, o caroço amassado e cozido na alimentação e o sumo das folhas como remédio (Costa e Oliveira, 1982; Passos, 1982; Resende e Moura, 1990).

Entre os maiores produtores mundiais estão os Estados Unidos e a China, revezando-se na posição de maiores produtores, seguidos pela Índia e o Paquistão, enquanto que os maiores importadores têm sido a China, a Indonésia e a União Européia. Contudo, o Brasil tem-se destacado como a maior nação importadora no ano agrícola de 1998 (Costa, 1999).

A produção comercial dessa malvácea distribui-se em 68 países, abrangendo uma área de 54 milhões de hectares. Atualmente no Brasil, a produção corresponde a 379 mil toneladas de algodão em pluma oriundas dos 650 mil hectares cultivados (Beltrão, 1999).

De acordo com Gonçalves (1994), o complexo cotonícola tem sido estratégico no desenvolvimento econômico das nações. Assim, ocorreu com a Inglaterra no século XIX, que tinha nessa indústria sua principal força competitiva, e com o Japão 
que, no período posterior à Segunda Guerra Mundial, teve, nas exportações de têxteis, a base de sustentação da sua recuperação econômica..

No cenário brasileiro, o algodão contribui, juntamente com outras matériasprimas agrícolas, para a geração de divisas desde a época colonial. Naquele período, sua importância resumia-se ao produto in natura. A partir da implantação do parque industrial, na década de 30, o algodoeiro passou a sustentar uma expressiva atividade econômica, seja pela exportação de produtos manufaturados têxteis ou de outros subprodutos (Moraes, 1997).

Até o início dos anos 80, o Brasil era importante produtor e exportador regular de algodão. A partir de 1988 aumentaram as importações, as quais passaram a ter participação crescente na composição da oferta total de algodão em pluma, em contraste com o padrão observado na década de 80, quando o volume importado era pouco significativo. Dessa forma, o volume produzido passou a apresentar nítida tendência de queda (Costa, 1999).

Santos (1993) e Moraes (1997) mencionaram que além de sua importância direta, a cultura algodoeira tem importante efeito multiplicador na economia nacional, tornando-se um dos grandes sustentáculos e absorvendo significativa mão-de-obra, pois os segmentos abrangidos e o seu processamento, compreendendo produção, beneficiamento, fiação, tecelagem e confecção, correspondem a uma significativa parcela da nossa economia. Do lado da demanda de insumos, seu cultivo exige significativas quantidades de fertilizantes e corretivos. Além disso, incrementa a demanda por máquinas e implementos, defensivos e sementes.

Segundo Santos (1999), vários fatores contribuem para a queda de produtividade do algodoeiro em todas as regiões do mundo, sendo um dos agroecossistemas mais sujeitos ao ataque de artrópodes-praga, atraindo e hospedando um complexo significativo de insetos e ácaros, os quais atacam raízes, caules, folhas, botões florais, maçãs e capulhos. Seus danos podem reduzir a produtividade, como também afetar diretamente certas características importantes das sementes e da fibra, depreciando-as consideravelmente para a utilização comercial. 
Predominantemente, duas espécies de algodoeiro de interesse comercial têm sido plantadas no Brasil: o arbóreo (Gossypium barbadense), caracterizado por ser uma planta perene, e o herbáceo (Gossypium hirsutum), planta anual. Apesar da boa qualidade da fibra e da resistência à seca, o baixo rendimento agronômico do algodoeiro arbóreo, fez com que sua exploração, por pequenos produtores, se limitasse quase que exclusivamente ao semi-árido brasileiro, em razão do uso de técnicas de produção rudimentares, formas arcaicas de exploração da terra, mecanismos viciados de comercialização, utilização de sementes não selecionadas, além da adversidade climática e do difícil acesso dos produtores ao crédito rural (Barros, Santos e Cavalcante, 1990; Moraes, 1997).

Historicamente, a produção do algodoeiro herbáceo, no Brasil, tem se situado nos Estados do Paraná e São Paulo, seguidos por Minas Gerais. Com menores produções, estão os Estados da Região Centro-Oeste, mas, recentemente, tem ocorrido alteração na composição da produção nacional. Nesse particular, as Regiões tradicionalmente importantes, representadas por São Paulo e Paraná vêm perdendo espaço. A Região do Brasil Central representada por parte de Minas Gerais (Triângulo Mineiro e Alto Paranaíba) e, especialmente, o Centro-Oeste tem conseguido a maior produção e os maiores avanços, esboçando-se uma tendência de deslocamento da cotonicultura brasileira rumo à Região Central do país (Moraes, 1997; Costa, 1999).

Em 1995, segundo a BM\&F, apenas 74,3\% das necessidades das indústrias têxteis paulistas e 39,6\% das necessidades das indústrias cearenses eram atendidas pela produção nacional. Já em 2002, segundo a mesma fonte, esses percentuais evoluíram para respectivamente 91,1\% e 70,9\%, figurando o Mato Grosso como maior fornecedor. A Bahia através do Programa de Incentivo à Cultura do Algodão no Cerrado Baiano (Proalba), pretende estimular a cotonicultura em sua região Oeste, de forma a se tornar o segundo estado maior produtor de fibra (Agrianual, 2002).

\subsubsection{Botânica e descrição}


O algodoeiro pertence ao grupo das plantas dicotiledôneas, família Malvaceae. O gênero Gossypium, ao qual pertence, é bastante variado e segundo Fryxell (1984), conta com 39 espécies, sendo 33 diplóides (31 selvagens e 2 cultivadas) e 6 tetraplóides (4 selvagens e 2 cultivadas).

As espécies cultivadas diplóides, conhecidas como algodoeiros do Velho Mundo, são Gossypium arboreum e Gossypium herbaceum. A primeira permanece com certa importância em regiões da Índia, Paquistão, China e Tailândia, e a segunda, ocupa uma área significativa apenas na Índia. A contribuição de ambas, para a produção mundial de algodão, não chega a 4\% (Fuzatto, 1999). As espécies tetraplóides cultivadas, ou algodoeiros do Novo Mundo, são G. hirsutum e G. barbadense. Esta última, conhecida como algodoeiro Pima, Egípcio ou Tanguis, produtora de fibra longa e de alta qualidade, é cultivada principalmente no Egito, Sudão, Peru e Estados Unidos e alguns países da antiga União Soviética. Pouco mais de 5\% da produção mundial de algodão é devida a espécie G. barbadense. Por outro lado, com distribuição em praticamente todos os países produtores, a espécie G. hirsutum, conhecida como algodoeiro "Upland", é responsável por mais de 90\% da produção mundial (Fuzatto, 1999).

Os cultivares, diferenciam-se quanto ao tamanho da fibra (curto, médio, longo), ciclo curto (120 a 140 dias); ciclo longo (150 a 180 dias), porte baixo ou alto, resistência a doenças, entre outras características.

O algodoeiro é uma planta ereta, anual ou perene, dotada de raiz principal cônica, pivotante, profunda, e com pequeno número de raízes secundárias grossas e superficiais. O caule herbáceo ou lenhoso, tem altura variável e é dotado de ramos vegetativos (4 a 5 intraxilares, na parte de baixo), e ramos frutíferos (extraxilares, na parte superior).

As folhas são pecioladas, geralmente cordiforme, de consistência coriácea ou não e inteiras ou recortadas (3 a 9 lóbulos). As flores são hermafroditas, axilares, isoladas ou não, cor creme nas recém abertas (que passa a rósea e purpúreo) com ou sem mancha purpúrea na base interna. Elas se abrem a cada 3-6 dias entre 9-10 horas da manhã. Os frutos (chamados "maçãs” quando verdes e "capulhos” pós-abertura) são 
cápsulas de deiscência (abertura) longitudinal, com 3 a 5 lojas cada uma, encerrando 6 a 10 sementes. As sementes são revestidas de pêlos mais ou menos longo, de cor variável, (creme, branco, avermelhado, azul ou verde) que são fibras (os de maior comprimento) e línter (os de menor comprimento). As fibras provêm das células da epiderme da semente e têm, como características comerciais, comprimento, finura, maturidade, resistência, entre outras.

Segundo Fuzzato (1999), embora haja diferenças devidas a variedades e condições ambientais, os estágios fenológicos do algodoeiro anual são: da emergência da plântula aos primeiros botões florais, decorrem de 30 a 35 dias; do aparecimento do botão à abertura da flor, entre 20 e 25 dias; da flor aberta ao fruto com tamanho máximo, 25 a 30 dias; e do fruto com tamanho máximo à deiscência, 30 dias.

O algodoeiro anual inicia o florescimento com cerca de 50 dias de idade, mantendo-o até 120 dias ou mais. O pico da curva de florescimento ocorre ao redor de 70 a 80 dias.

\subsection{Aspectos bioecológicos de Nezara viridula e Piezodorus guildinii}

\subsubsection{Nezara viridula (Linnaeus, 1758)}

Nezara viridula foi originalmente descrito por Linnaeus em 1758, com o nome científico de Cimex viridula, com base em exemplares coletados na Índia (Jones, 1985). A espécie é presumivelmente originária do sudoeste da Ásia (Yukawa \& Kiritani, 1965) e, posteriormente, espalhou-se pelo Novo Mundo (Dewitt \& Godfrey, 1972). Muitos autores têm discutido o centro de origem desta espécie (Todd, 1989), mas ainda não chegaram a um consenso. Entretanto, muito provavelmente $N$. viridula originou-se da Região Etiópica (Hokkanen, 1986).

Segundo Lethierry \& Severin (1893), citados por Panizzi \& Slansky (1985), trata-se de uma espécie cosmopolita, ocorrendo em regiões tropicais e subtropicais da 
Europa, Ásia, África e América, sendo, segundo Grazia (1977), a única espécie do gênero Nezara encontrada na Região Neotropical.

Dentre os percevejos que atacam a soja, $N$. viridula é considerado o mais importante. Os adultos medem 12 a 15 mm, podendo as fêmeas sobreviver até 30 dias, enquanto os machos vivem cerca de 15 dias (Mitchel \& Mau, 1971).

O processo de reprodução inicia-se em 3 dias, sendo o período de préoviposição variável entre 6 e 16 dias, enquanto a oviposição pode durar entre 14 e 21 dias (Kiritani \& Kokyo, 1962) .

A fêmea faz a postura na face inferior das folhas ou nas partes mais abrigadas das plantas e cada uma põe até 200 ovos, agrupados em placas hexagonais, de coloração inicial amarelada e próxima a eclosão, rosada (Gallo et al, 2002). Após a eclosão, as ninfas de primeiro ínstar permanecem aglomeradas ao redor dos ovos. Nesta fase possuem forma ovalada, coloração geral marrom avermelhada e cápsula cefálica vermelha, medindo aproximadamente $1,3 \mathrm{~mm}$, permanecendo 3 dias neste estádio (Corpuz, 1969).

No segundo ínstar as ninfas ainda apresentam hábito gregário, causando danos pouco expressivos. Essa agregação nos primeiros ínstares de $N$. viridula, parece ter efeito sobre a taxa de desenvolvimento e mortalidade (Kiritani, 1964; Kiritani et al, 1966; Kiritani \& Kimura, 1965). Apresenta cor preta, cápsula cefálica marrom, com 4 a 6 manchas claras no abdome. A duração deste ínstar é de aproximadamente 6 dias, com as ninfas medindo 3,4 mm (Rizzo, 1968).

A partir do terceiro ínstar inicia o período normal de alimentação, uma vez que o aparelho bucal já está plenamente desenvolvido. No tórax há a presença de uma mancha em forma de "T" invertido e no abdome encontram-se 22 manchas de formato irregular, brancas ou amareladas, dispostas em 4 linhas que convergem em direção à extremidade anal. Este ínstar tem duração média variável de 3 a 6 dias (Corpuz, 1969).

As ninfas de quarto ínstar apresentam cor geral verde ou escurecida, sendo esta dicromia atribuída à baixa temperatura (Harris et al, 1984) ou a densidade populacional (Kiritani, 1964). Sobre o tórax pode ser vistas 4 fileiras, cada uma contendo 3 pontuações pretas. Nas bordas do abdome existem 12 manchas de cor rosada. A face 
ventral do abdome apresenta a mesma coloração geral do dorso. As ninfas permanecem neste estádio por 4 dias aproximadamente (Corpuz, 1969).

Em soja, ninfas de quarto e quinto ínstares de $N$. viridula e $P$. guildinii, são as principais responsáveis pela dispersão do inseto imaturo em uma determinada área, as quais se deslocam andando tanto no sentido longitudinal (ao longo das fileiras) como no sentido transversal (perpendicular às fileiras) atingindo distâncias variáveis (Panizzi et al, 1980).

Em sementes de soja, Duncan \& Walker (1968), verificaram que adultos de $N$. viridula causam um maior número de puncturas do que ninfas de quarto e quinto instar; já Todd \& Turnipseed (1974), Yergan (1977) e McPherson et al. (1979) indicaram que ninfas de quinto ínstar e adultos de $N$. viridula causam danos mais significativos que os demais ínstares. Em maçãs de algodão, maiores danos são causados por ninfas de quinto ínstar comparados com os demais ínstares ou adultos (Greene et al, 1999). Possuem cor geral verde e antenas escuras. Uma listra amarela está presente sobre os olhos, notandose uma mancha rosa atrás deles. Na ligação da cabeça com o tórax, podem ser encontradas duas manchas pretas. Há o surgimento das tecas alares, com uma pontuação escura no centro de cada uma. Podem permanecer neste estádio de 7 a 10 dias (Kiritani \& Hokyo, 1962; Corpuz, 1969), podendo apresentar um desenvolvimento mais lento (hibernação parcial) com a diminuição da temperatura (Ferreira e Panizzi, 1982). Após o quinto ínstar, o inseto já adulto, apresenta cor geral verde escura, às vezes com reflexos castanhos, com o segundo par de asas membranosas.

Este percevejo exala, por meio de glândulas localizadas no metaepisterno (adultos), um odor desagradável, que inclui aldeído como componente principal e cuja função é servir como defesa. A exalação desta substância pode atuar como feromônio de alarme, uma vez que as colônias se desagregam na presença do odor, voltando a juntarse posteriormente em outro local.

\subsubsection{Piezodorus guildinii (Westwood, 1837)}


De acordo com os trabalhos de Corseuil et al, 1974; Costa \& Link, 1974; Panizzi, 1975 e Waldbauer, 1977, ninfas de primeiro ínstar, possuem a coloração geral ferrugínea, brilhante, destituído de pontuações; abdome predominante vermelho, às vezes amarelado. Estas permanecem aglomeradas em torno da postura e medem cerca de $1 \mathrm{~mm}$ de comprimento. Na segunda fase ninfal, medem entre 2 e $3 \mathrm{~mm}$, possuindo coloração ferrugínea na cabeça, abdome vermelho dotado de pontuações ferrugíneas.

A partir do terceiro ínstar até a fase adulta, a metamorfose não é tão pronunciada, como ocorre com o percevejo verde, medindo entre 4 e $5 \mathrm{~mm}$ de comprimento. Ninfas de quarto ínstar, apresentam a cabeça com 3 faixas longitudinais ferrugíneas e o noto apresenta 4 faixas, intercaladas por faixas amareladas. As placas laterais são totalmente ferrugíneas ou apenas numa faixa estreita junto à margem lateral dos urotergitos, sendo o restante da placa pontuado. Nesta fase, as ninfas medem de 5 a 6 mm de comprimento (Panizzi \& Smith, 1977).

No quinto ínstar, a coloração geral é amarelada com pontuações ferrugíneas na cabeça, pronoto, pterotecas, escutelo, placas medianas e placas laterais, estas com a estreita faixa escura na margem lateral dos segmentos. Pronoto trapezoidal, com largura inferior à largura abdominal. Pterotecas atingindo o meio do terceiro urotergito. Nesta fase, as ninfas medem $8 \mathrm{~mm}$ de comprimento (Panizzi \& Smith, 1977). O adulto apresenta coloração esverdeada, brilhante, que ao final da fase sofre uma descoloração, tendendo ao amarelo pálido. Seu comprimento varia entre 10 e $12 \mathrm{~mm}$. Possui uma mancha escura na metade posterior do pronoto, podendo apresentar um fundo avermelhado. A longevidade dos adultos é de aproximadamente 34 a 38 dias para machos e 41 a 45 dias para fêmeas. Estes autores obtiveram um número médio de 15 ovos por massa colocados, principalmente nas vagens e, em menor proporção, nas folhas e hastes. Em média cada fêmea oviposita 3 massas durante sua vida, sendo o período de pré-oviposição de 22 dias. Os ovos são de cor preta, depositada em fila dupla, apresentando a forma de um barril, com a presença de uma pilosidade na extremidade superior. O período de incubação varia de 3 a 9 dias. 
O percevejo pequeno é de controle mais difícil que o percevejo verde, pois é sensível a um número menor de inseticidas. Os danos causados, em geral, são semelhantes aos do percevejo verde.

\subsection{Danos causados em maçãs de algodoeiro por percevejos migrantes de lavouras de soja}

No Brasil Central, a soja é plantada no período de 20 de outubro a 10 de dezembro, possuindo um ciclo médio em torno de 120 dias, com colheita prevista de fevereiro a maio. Durante os diferentes estádios de crescimento e desenvolvimento, essa cultura é atacada por diversos insetos-praga, destacando-se os percevejos da família Pentatomidae, que causam danos expressivos desde a formação das vagens até o final do desenvolvimento das sementes. Para o algodão, a época de plantio recomendada para a Região Centro-Oeste é de 01 de outubro a 30 de dezembro, com um ciclo de crescimento variando de 130 dias (variedades precoces) a 180 dias (variedades tardias), ocasionando período de colheita que se estende de abril a agosto (Arantes et al., 1998).

Assim como a cultura da soja, o algodoeiro também é atacado por percevejos que comprometem seriamente a sua produção. Durante a colheita da soja (fevereiro a maio), o algodoeiro estará com aproximadamente 90 dias, encontrando-se no final da fase vegetativa e início da reprodutiva, ou seja, quando estiver apresentando os primeiros botões florais (Marur \& Ruano, 2002). De acordo com esses autores, nesse estádio de desenvolvimento a cultura algodoeira é atacada por percevejos, incluindo-se os que migram da cultura da soja, por ocasião da colheita, sendo também a fase determinante da produção.

O hábito indeterminado de crescimento do algodoeiro torna-o morfologicamente complexo, uma vez que os desenvolvimentos vegetativo e reprodutivo ocorrem simultaneamente (Mauney, 1984).

Embora haja alguma variação em função da posição na planta, pode-se estimar que a cada três dias deva aparecer um botão floral em ramos sucessivos (Figura 1) e a cada seis dias, um botão floral no mesmo ramo (Kerby \& Keeley, 1987). Nessa fase, o 
crescimento vegetativo é fundamental para gerar um grande número de posições frutíferas. Por ocasião do aparecimento da primeira flor (branca), uma planta com bom potencial de produção deve ter 9 a 10 nós acima dessa flor (Kerby \& Hake, 1993).

A fixação dos frutos reflete na produção de algodão em caroço, e mais acentuadamente na produção de fibras (Rosolem, 2001).

Em relação aos componentes de produção, 80-90\% dos frutos originam-se de flores abertas no primeiro mês de florescimento. Vários fatores ambientes influem positiva ou negativamente na viabilização das flores e dos frutos (maçãs), desde 23 dias antes da antese e pôr um período que se completa em 50 dias (Gridi-Papp, 1965).

Nesse período ocorrem também o processo de formação e desenvolvimento da fibra, que compreende as fases de alongamento (da fibra) e deposição da celulose as quais ocorrem predominantemente a partir de 15 até 55 dias após antese (Benedict, 1984).

Kerby \& Keeley (1987) observaram em algodão com produtividade de 3.630 $\mathrm{Kg} / \mathrm{ha}$, que $66 \%$ da produção estavam na primeira posição, 28\% na segunda e 6\% na terceira posição, a partir da haste principal, sendo o peso das maçãs de 8, 4,5 e 3 g respectivamente. Nessa fase, da primeira flor à abertura do primeiro capulho, algumas maçãs já estão em fase de maturação. Portanto, na segunda metade dessa fase a ocorrência de qualquer estresse ocorrerá, além do prejuízo pela queda de estruturas, um prejuízo em função da ocorrência de maior porcentagem de fibras imaturas (Rosolem, 2001). 


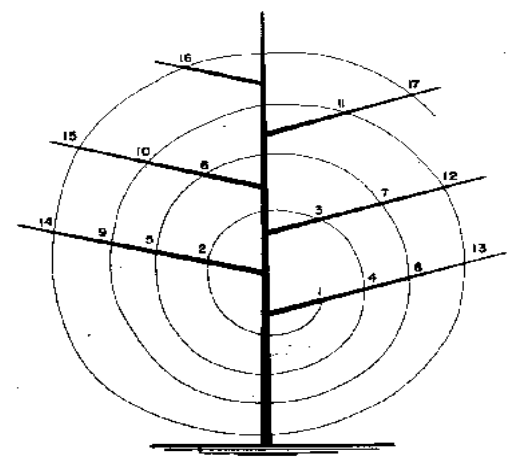

Figura 1- Sucessão de flores do algodoeiro (Nakano et al., 1981)

Todd (1989) relata que várias espécies do gênero Nezara, em especial $N$. viridula, provocam danos nos algodoeiros da África, sul da Europa, regiões tropicais e subtropicais da Ásia, partes da Austrália, algumas regiões dos Estados Unidos, Nova Zelândia, América do Sul e Central.

Greene et al. (1999) constataram que ninfas de $N$. viridula de quinto instar, em maçãs com 9 dias de idade por 3,5 dias, causaram mais injúrias que percevejos adultos ou em outros ínstares. Os danos de $N$. viridula em quinto ínstar diminuíram com o aumento da idade das maçãs de 4 a 18 dias após a florada, sendo que, após 18 dias, os danos foram insignificantes. Maçãs com 18 dias após a florada, expostas à $N$. viridula de quinto ínstar por 7 dias, reduziram em 59\% a produção em comparação com maçãs não expostas. Adultos de L. lineolaris causaram injúrias nas maçãs, similares às ninfas de quarto ínstar de $N$. viridula após confinamento de adultos, individualmente, em maçãs de 8 dias de idade por 8 dias.

Bundy et al. (2000) expuseram maçãs de tamanhos pequenos e médios aos percevejos N. viridula, Acrosternum hilare e Euschistus servus por um período de 48 horas. As maçãs foram examinadas interna e externamente aos 2, 4, 6, 8 e 10 dias após a alimentação. Concluíram que não houve relação entre a quantidade de marcas de alimentação externa e verrugas internas, formadas no interior das maçãs perfuradas, e 
que aproximadamente $20 \%$ das maçãs danificadas com verrugas internas correspondem às marcas externas.

Ribeiro et al. (2000) constataram em amostras provenientes do Mato Grosso, Mato Grosso do Sul e Bahia, enviadas ao Laboratório de Fitossanidade da Universidade Federal de Mato Grosso do Sul (UFMS), que muitas maçãs não tinham sintomas externos visíveis, mas todas apresentavam sintomas de podridão interna. Em algumas amostras, foram detectados danos causados por percevejos (populações migrantes de Euschistus herus e P. guildinii da soja e percevejos-rajados do algodoeiro). Foram encontrados três gêneros de fungos (Fusarium, Aspergillus e Colletotrichum) e um gênero de bactéria (Erwinia). A alta umidade no período de frutificação, também pode ter influenciado na elevada incidência destes microorganismos (Ribeiro et al., 2000). Segundo Greene et al. (2001), A. hilare, N. viridula e E. servus foram os fitófagos predominantes em algodoeiro na Carolina do Sul entre 1995-1997. Estas espécies ocorreram tanto nas variedades convencionais como na transgênica "NuCOTN33B", contendo o gene de expressão do CryIA@ delta-endoxina do Bacillus thuringiensisi Berlinier var. kurstaki. O adulto de $N$. viridula migra para o algodão, proveniente de cultivares hospedeiras durante o mês de julho, reproduzindo-se nos plantios tardios de algodão de julho até setembro.

Ribeiro et al. (2001) avaliaram a resistência de diferentes genótipos de algodoeiro (Ita-90; Cd-401; Cd-402; Cd-403; Cd-404; Fibermax; Delta Opal e Factual) às espécies de percevejos Niesthtea sidae, E. heros, $N$. viridula e Dysdercus sp.) e constataram que todos foram igualmente atacados, não ocorrendo diferenças significativas.

Berger et al. (2001) constataram que as variedades Delta Opal e Ita 90 foram igualmente suscetíveis às injúrias de percevejos e que há uma correlação entre a intensidade de aparecimento de “pinta preta” com a percentagem de maçãs com puncturas de percevejos. Popich \& Videla (2001), em experimento realizado em Santiago Del Estero (Argentina), analisaram os danos ocasionados por diversas espécies de percevejos (Jadera choprai, Dysdercus chaquensis, Thyanta pallidovirens, $N$. viridula, Edessa meditabunda, Corizus sidae, P. guildinii e Sericophanes sp.) em maçãs 
de algodoeiros transgênicos e convencionais. Não foram observadas preferências de alguma espécie por qualquer uma das variedades. Aborto de botões florais coincidiram com o aumento da aparição de quase todos os hemípteros na cultura.

\subsection{Criação de percevejos (Pentatomidae) em laboratório}

Diversas pesquisas têm sido realizadas no sentido de se conseguir uma dieta artificial para criação de insetos sugadores fitófagos, mas devido aos seus hábitos alimentares e às diferenças nutricionais requeridas, não tem tido tanto sucesso, como no caso dos mastigadores.

Uma dieta composta de grãos de feijão verde e amendoim cru foi utilizada por Harris \& Todd (1981). Por sua vez, Corrêa-Ferreira (1985) inicialmente, sugeriu o uso de sementes secas de soja como alimento, pela praticidade na produção massal. Porém como a mortalidade é alta nesta dieta, foi recomendada a complementação com plantas de soja com vagens para a criação das ninfas, sendo somente os adultos criados nas sementes secas. Harris \& Todd (1981) mencionaram que o inseto pode ser criado utilizando-se somente feijão verde, porém a adição de amendoim melhora a performance dos insetos. A diversificação dos alimentos (soja, amendoim, feijão, milho) resulta em adultos mais sadios e com uma performance melhor (Corrêa-Ferreira, 1985).

No Japão, $N$. viridula é criado em dois tipos de dietas; uma consistindo de sementes secas de soja e amendoim cru; a outra composta destes dois elementos com a adição de sementes de trevo vermelho. A água é oferecida aos insetos com vitamina C (ácido ascórbico).

Harris \& Todd (1981) e Jones (1985) utilizaram tiras de papel como substrato de oviposição. Segundo Corrêa-Ferreira (1985) as fêmeas ovipositam 2,5 vezes mais em plantas de soja do que em outros substratos, e portanto sugeriu a utilização das plantas (mesmo em estágio vegetativo) nas gaiolas de adultos como um estímulo e suporte para postura. 
Todos esses métodos são viáveis em pequenas criações de percevejos, mas, como dependem da troca contínua e periódica do alimento utilizado, tornam-se praticamente inviáveis quando em criações de grande porte.

Panizzi et al. (2000), pela primeira vez, demonstraram um modelo de criação simulando uma planta natural como substrato para a colocação de ovos por adultos de $N$. viridula, em conjunto com uma dieta artificial seca para a criação de ninfas. As ninfas alimentaram-se normalmente da dieta, embora o tempo de desenvolvimento tenha sido maior ou igual ao das ninfas que se alimentaram de vagens de soja. A mortalidade total das ninfas foi baixa tanto na dieta como na vagem de soja.

Para estabelecimento de uma criação de $N$. viridula em laboratório, adultos provenientes de campo ou de criações em laboratórios, devem ser sexados e colocados em gaiolas teladas na proporção de um macho para cada fêmea, num total de 50 casais por gaiola (Costa, 1991) e mantidos, segundo Corrêa-Ferreira (1993), em salas climatizadas sob condições adequadas de temperatura $\left(25 \pm 2^{\circ} \mathrm{C}\right)$, de umidade $(65 \pm$ 10\%) e de fotofase (14 horas). As gaiolas de multiplicação têm a estrutura de madeira medindo 50 x 40 x 40 cm (Costa, 1991) ou 50 x 50 x 70 cm (Corrêa - Ferreira, 1993), abertas na frente para limpeza, coleta e manipulação dos insetos e são cobertas com tela branca de malha fina.

Nas gaiolas, o alimento constituído por sementes secas de soja e amendoim é colocado em tiras de papel branco que ficam suspensas num carrossel central que sustenta na sua porção superior, uma calha de celulóide ou alumínio, com algodão umedecido. Na gaiola é colocada uma planta de soja, que servirá como substrato de oviposição aos adultos, e eventualmente, como suplementação nutricional. Em torno de seis dias após a oviposição, as primeiras ninfas começam a eclodir. Estas são transferidas para as gaiolas teladas até o início da alimentação, no segundo ínstar . Para a criação das ninfas são utilizadas, como alimento, plantas de soja com vagens (CorrêaFerreira,1993). 


\section{MATERIAL E MÉTODOS}

O experimento foi realizado na Fazenda Areão, da ESALQ/USP, no município de Piracicaba, SP.

A semeadura foi realizada no dia 3 de janeiro de 2002 , com espaçamento de 1 metro entre linhas e uma densidade de 8 plantas por metro. Os tratos culturais foram realizados com base na recomendação da pesquisa para a cultura do algodão.

O cultivar utilizado foi o Delta Opal, cujas características agronômicas fornecidas pela MDM ( Maeda Deltapine Monsanto Algodão) é a seguinte:

- $\quad$ Porcentagem de fibra : 39 - $42 \%$

- Índice Micronaire: 3,8 - 4,4

- Comprimento de fibra (mm): 30 - 33

- Uniformidade de comprimento de fibra - (INDEX): 84,7

- Elongação da fibra (\%): 7,1

- Reflectância (\%): 75,6

- $\quad$ Tenacidade de ruptura da fibra (gf/tex): 29,2

- Peso de capulho (g): 5,0 - 6,0

- $\quad$ Peso de 100 sementes (g): 90 - 105 


\subsection{Criação de $N$. viridula e P. guildinii}

A criação de $N$. viridula e $P$. guildinii foi realizada em laboratório de Entomologia Econômica do Departamento de Entomologia, Fitopatologia e Zoologia Agrícola da ESALQ/USP.

Adultos de $N$. viridula e $P$. guildinii foram coletados em lavouras de soja da região de Piracicaba, SP. A coleta desses percevejos em campo se estendeu durante toda a realização do experimento.

A metodologia utilizada para a criação dos percevejos, foi semelhante àquela descrita por Corrêa-Ferreira (1985), com algumas modificações em relação ao tamanho das gaiolas e às condições do Laboratório de Entomologia da ESALQ/USP, mantido a $24 \pm 1{ }^{\circ} \mathrm{C}$; UR de $60 \pm 10 \%$ e fotofase de 14 horas.

Para a manutenção dos adultos, foram utilizadas gaiolas de 50 x 50 x $40 \mathrm{~cm}$, confeccionadas em madeira, revestidas com telas de náilon e com porta frontal para limpeza, coleta e manipulação dos insetos.

Internamente, foi colocado um vaso com uma planta de soja (em fase de desenvolvimento vegetativo) como substrato (e atraente) de oviposição, e um suporte de madeira (30 x $20 \mathrm{~cm}$ ) com uma armação de arame, na qual foram penduradas tiras de papel do tipo sulfite de $5 \mathrm{~cm}$ de largura e $15 \mathrm{~cm}$ de comprimento, contendo sementes de soja e/ou amendoim, coladas às tiras por meio de cola comum, e também placas de Petri, contendo vagens de soja, constituindo a alimentação dos adultos, trocados regularmente. Foram adicionadas duas placas plásticas com $6 \mathrm{~cm}$ de diâmetro cada, por gaiola, contendo algodão umedecido em água destilada, trocada diariamente.

Os ovos foram coletados diariamente e colocados em placas plásticas de $6 \mathrm{~cm}$ de diâmetro, contendo papel filtro umedecido com água destilada, e acondicionados na BOD a $25^{\circ} \mathrm{C}$ e UR $70 \%$.

As ninfas foram mantidas em placas plásticas de $20 \mathrm{~cm}$ de diâmetro, cuja tampa possuía uma abertura de $5 \mathrm{~cm}^{2}$, e colado, com cola de silicone quente, uma tela de voil. No seu interior, foram colocadas placas plásticas com algodão umedecido e vagens de soja, às quais foram mantidas na BOD nas condições acima descritas. 


\subsection{Influência de $N$. viridula e P. guildinii na queda de maçãs}

Este ensaio visou o estudo da influência dos percevejos $N$. viridula e $P$. guildinii na queda de maçãs em início de desenvolvimento, na fase intermediária e próxima a abertura do capulho.

Para a proteção da florada e das maçãs formadas, foram confeccionados saquinhos de voil de 20 x 15 cm costurados à máquina, com abertura em um dos lados menores. Em seu interior, foi colocado um copo plástico de 200 ml (copos de água descartáveis) sem o fundo, como uma forma de proteção e também de armação, de modo que a flor do algodão se alojasse dentro do copo, e o saquinho cobrisse o copo e a flor, sendo amarrado no ramo secundário, e não no pedúnculo, para impedir o acesso de insetos às maçãs que irão se formar.

O período de desenvolvimento das maçãs foi dividido em 3 fases:

- $1^{\underline{a}}$ fase : maçãs com até 10 dias após a florada;

- 2 $2^{\underline{a}}$ fase : maçãs com 11 a 20 dias após a florada, e

- $3^{\underline{a}}$ fase : maçãs após 21 dias da florada.

Para haver uma padronização, os dias foram contados a partir do momento em que a flor se desprendia facilmente da maçã, quando então era devidamente etiquetada e datada.

Para verificar a queda de maçãs causadas pelos percevejos $N$. viridula e $P$. guildinii, estes foram acondicionados no interior dos saquinhos e colocados em contato com as maçãs em suas respectivas fases e protegidos pelo copo plástico.

\section{Tratamento I:}

$1^{\underline{a}}$ Fase (maçãs com até 10 dias após a florada)

Nezara viridula - 1 percevejo por maçã - 10 maçãs

Piezodorus guildinii -1 percevejo por maçã - 10 maçãs

Testemunha - sem percevejo - 10 maçãs 


\section{Tratamento II:}

$1^{\underline{a}}$ Fase (maçãs com até 10 dias após a florada)

Nezara viridula - 2 percevejos por maçã - 10 maçãs

Piezodorus guildinii - 2 percevejos por maçãs - 10 maçãs

Testemunha - sem percevejo - 10 maçãs

\section{Tratamento III:}

$2^{\mathrm{a}}$ Fase (maçãs com 11 a 20 dias após a florada)

Nezara viridula - 1 percevejo por maçã - 10 maçãs

Piezodorus guildinii -1 percevejo por maçã - 10 maçãs

Testemunha - sem percevejo - 10 maçãs

\section{Tratamento IV:}

$2^{\text {a }}$ Fase (maçãs com 11 a 20 dias após a florada)

Nezara viridula - 2 percevejos por maçã - 10 maçãs

Piezodorus guildinii - 2 percevejos por maçãs - 10 maçãs

Testemunha - sem percevejo - 10 maçãs

\section{Tratamento V:}

$3^{\text {a }}$ Fase (maçãs acima de 21 dias após a florada)

Nezara viridula - 1 percevejo por maçã - 10 maçãs

Piezodorus guildinii -1 percevejo por maçã - 10 maçãs

Testemunha - sem percevejo - 10 maçãs 


\section{Tratamento VI:}

$3^{\underline{a}}$ Fase (maçãs acima de 21 dias após a florada)

Nezara viridula - 2 percevejos por maçã - 10 maçãs

Piezodorus guildinii - 2 percevejos por maçãs - 10 maçãs

Testemunha - sem percevejo - 10 maçãs

Para cada tratamento, foram realizadas quatro repetições. As maçãs foram escolhidas ao acaso, conforme as datas, evitando-se as do terço inferiores. Os percevejos ficaram acondicionados por 7 dias, sendo realizadas repetições quando ocorriam mortes antes do prazo previsto.

\subsection{Efeito do ataque de $N$. viridula e $P$. guildinii, nas características tecnológicas da fibra, fio e componentes de produção do algodoeiro}

Com a finalidade de avaliar as injúrias causadas às características tecnológicas das fibras do algodão por exposição de maçãs em 3 estágios de desenvolvimento vegetativo aos percevejos $N$. viridula e $P$. guildinii, foi realizado o presente ensaio.

A metodologia foi semelhante à descrita no ensaio anterior, havendo, porém, novas repetições no caso de queda de maçãs.

\subsection{Colheita e amostras para análise}

Foram realizadas 3 colheitas manuais aos 130, 145 e 160 dias após a germinação, e colhidos somente capulhos com lojas totais ou parcialmente abertas, deixando de colher capulhos com lojas não abertas, a fim de se verificar o tipo de dano ocorrido nas fibras que poderiam ser utilizadas nos processos industriais. Todo o material colhido foi acondicionado em sacos de papel. 
De cada tratamento, retirou-se uma amostra de 20 capulhos, conforme recomendação da Seção de Fibras do Instituto Agronômico de Campinas, São Paulo, onde foram enviadas para avaliar as qualidades físicas do algodão que afetam a qualidade do produto acabado e/ou a eficiência no setor industrial.

Esta avaliação é realizada pelo método denominado “classificação HVI (High Volume Insruments)”, cujas análises são: Características tecnológicas das fibras e do fio: comprimento da fibra, uniformidade de comprimento de fibra, índice de fibras curtas, tenacidade de ruptura da fibra (gf/tex), maturidade (\%), índice Micronaire, finura da fibra, reflectância e componentes de produção: peso de 100 sementes (g), peso de 1 capulho (g) e porcentagem de fibra. 


\section{RESULTADOS E DISCUSSÃO}

\subsection{Influência de $N$. viridula e P. guildinii na queda de maçãs}

As evoluções sintomáticas dos danos causados pelas sucessivas picadas dos percevejos, podem ser visualizadas na Figura 2 A, lesões externas, na Figura 2 B observam-se as lesões internas, com a formação de verrugas, e na Figura 2 C, danos ocorridos nas fibras.
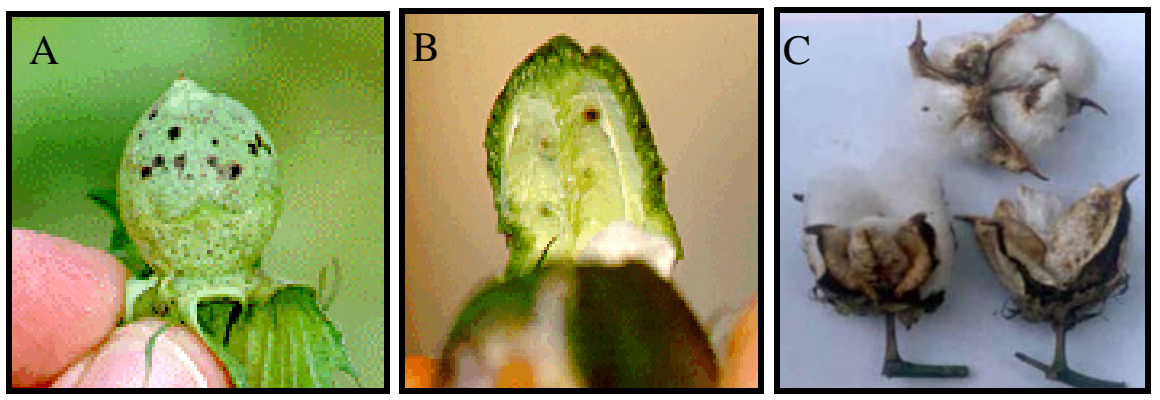

Figura 2- Lesões externas (A), internas (B) e nas fibras (C)

Pelos dados obtidos (Tabelas 1 e 2) observaram-se que os percevejos $N$. viridula e P. guildinii foram responsáveis pela queda das maçãs que se desenvolveram na primeira fase e que tanto 1 como 2 percevejos por maçã causaram o mesmo dano, afetando de 55-60\% a queda dessas maçãs (descontando os 10\% de queda natural, obtido na testemunha).

Tais dados estão de acordo com Greene et al (1999) que afirmaram que $N$. viridula causa prejuízo nas maçãs aos 9 dias de idade. Para a segunda fase os autores 
concluíram que houve 59\% na redução da produção, expondo as maçãs com 18 dias de idade; entretanto para esta fase o dano obtido foi de apenas 15 a 30 \% (descontada a queda natural de 2,5\% para $P$. guildinii e 5\% para $N$. viridula). Diversos outros autores relatam os danos causados pelos percevejos nas maçãs do algodoeiro, mas citam apenas injúrias causadas pelas picadas ou pelas manchas deixadas pelos mesmos, ou então fungos que poderiam ter penetrado através das picadas produzidas por este tipo de praga.

Nota-se também que mesmo na terceira fase, isto é, maçãs com mais de 20 dias de idade podem sofrer danos consideráveis de 2,5 a 15\% na redução da produção, o que significa um valor acima dos níveis normais para controle destas pragas (Tabelas 1 e 2).

Tabela 1. Porcentagem de queda de maçãs em 3 densidades de infestação de Nezara viridula e em 3 fases de desenvolvimento das maçãs. Piracicaba, SP, 2002

\begin{tabular}{|c|c|c|c|c|}
\hline \multirow{2}{*}{$\begin{array}{l}\text { Densidade de } \\
\text { Infestação }\end{array}$} & \multicolumn{3}{|c|}{ Fases de desenvolvimento das maçãs } & \multirow{2}{*}{ Média } \\
\hline & $1^{\mathbf{a}}$ & $2^{\underline{a}}$ & $3^{\mathbf{a}}$ & \\
\hline 1 & $70,00 \mathrm{aA}$ & $27,50 \mathrm{aB}$ & $5,00 \mathrm{aC}$ & $34,20 \mathrm{a}$ \\
\hline 2 & $67,50 \mathrm{aA}$ & $35,00 \mathrm{aB}$ & $2,50 \mathrm{aC}$ & 35,00 a \\
\hline 0 & $10,00 \mathrm{bA}$ & $5,00 \mathrm{bA}$ & $0 \mathrm{aA}$ & $5,00 \mathrm{~b}$ \\
\hline Média & $49,20 \mathrm{~A}$ & $22,50 \mathrm{~B}$ & $2,50 \mathrm{C}$ & 24,70 \\
\hline
\end{tabular}

Médias seguidas por letras distintas, minúsculas na coluna e maiúsculas na linha, diferem entre si pelo teste de Tukey $(\mathrm{P} \leq 0,05)$. 
Tabela 2. Porcentagem de queda de maçãs em 3 densidades de infestação de Piezodorus guildinii e em 3 fases de desenvolvimento das maçãs. Piracicaba, SP, 2002

\begin{tabular}{ccccc}
\hline $\begin{array}{c}\text { Densidade de } \\
\text { infestação }\end{array}$ & \multicolumn{2}{c}{ Fases de desenvolvimento das maçãs } & \multirow{2}{*}{ Média } \\
\hline 1 & $\mathbf{1}^{\mathbf{a}}$ & \multicolumn{1}{c}{$\mathbf{2}^{\mathbf{a}}$} & \multicolumn{1}{c}{$\mathbf{3}^{\mathbf{a}}$} & \\
2 & $62,50 \mathrm{aA}$ & $20,00 \mathrm{aB}$ & $15,00 \mathrm{aB}$ & $32,50 \mathrm{a}$ \\
0 & $65,00 \mathrm{aA}$ & $17,50 \mathrm{aB}$ & $7,50 \mathrm{aB}$ & $30,00 \mathrm{a}$ \\
Média & $10,00 \mathrm{bA}$ & $2,50 \mathrm{aA}$ & $0 \mathrm{aA}$ & $4,20 \mathrm{~b}$ \\
\hline
\end{tabular}

Médias seguidas por letras distintas, minúsculas na coluna e maiúsculas na linha, diferem entre si pelo teste de Tukey $(\mathrm{P} \leq 0,05)$.

As Figuras 3 e 4 mostram que $N$. viridula e $P$. guildinii têm uma correlação significativa entre quantidade de percevejo e queda de maçãs, na ordem de 13,57 + $44,23 \mathrm{x}^{0,5}$ e $12,51+41,04 \mathrm{x}^{0,5}$ respectivamente até 10 dias após a florada. Já para a segunda e terceira fases, não houve correlação significativa entre o aumento do número de percevejos e porcentagem de queda para ambas as espécies.

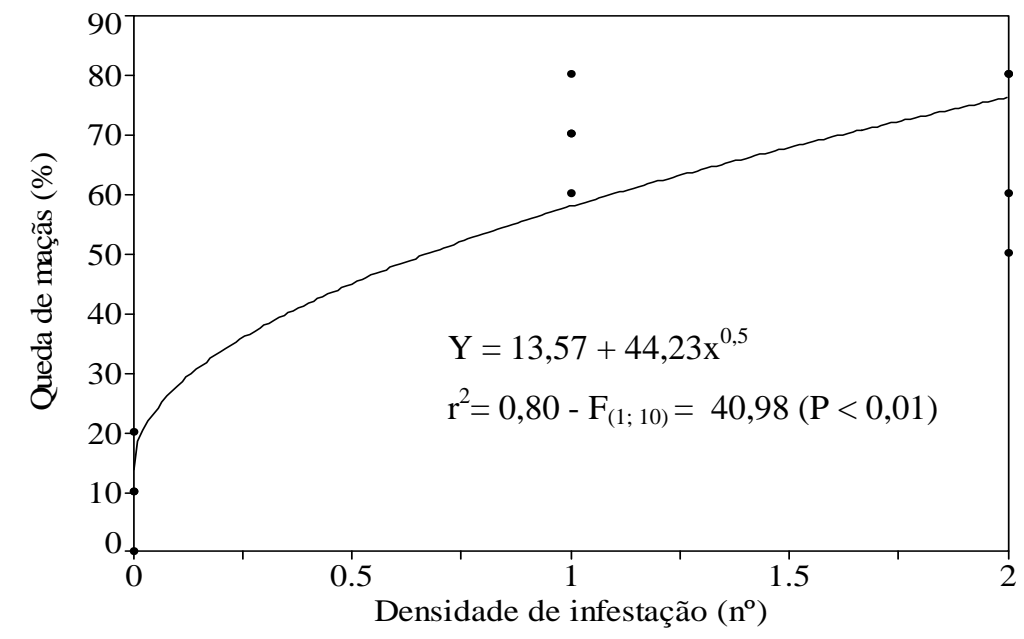

Figura 3- Relação entre densidade de infestação de $N$. viridula e queda de maçãs de algodoeiro (\%) até 10 dias de idade após a florada. Piracicaba, SP, 2002 


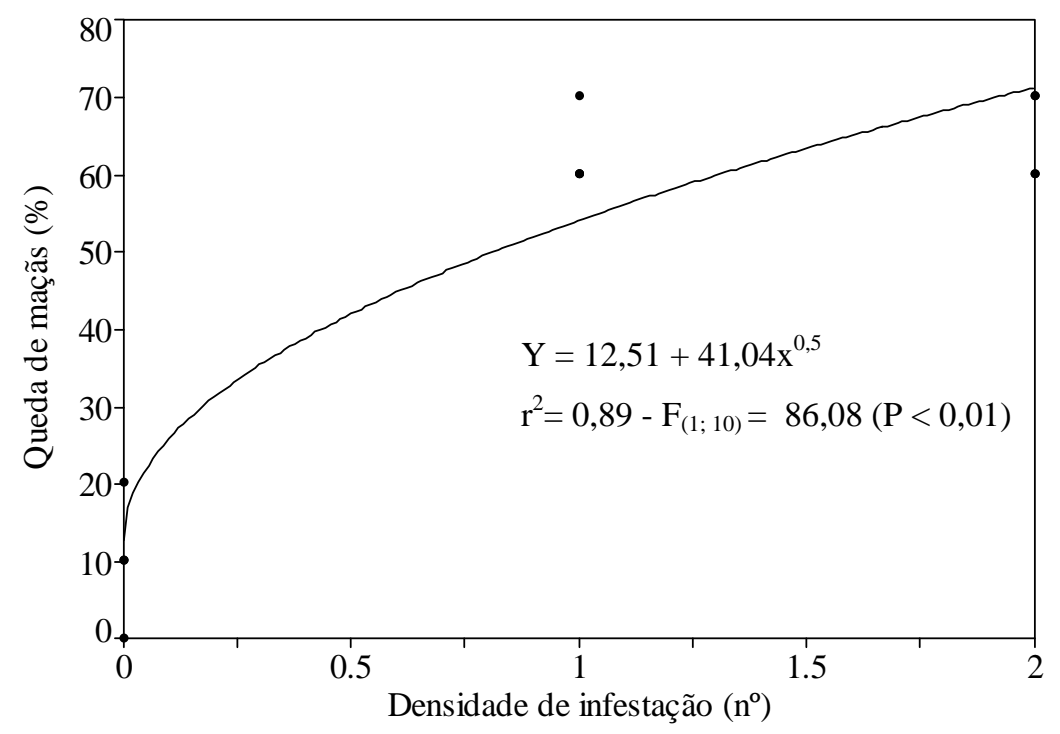

Figura 4- Relação entre densidade de infestação de $P$. guildinii e queda de maçãs de algodoeiro (\%) até 10 dias de idade após a florada. Piracicaba, SP, 2002

4.2 Danos causados por $N$. viridula e $P$. guildinii, nas características componentes de produção, tecnológicas da fibra e do fio do algodoeiro

\subsubsection{Efeito das espécies em relação aos danos ocorridos nas características componentes de produção (peso de capulho, peso de 100 sementes e porcentagem de fibra)}

Verifica-se, na Tabela 3, que em relação ao peso de capulhos, P. guildinii causou danos significativos em maçãs com até 20 dias de idade, enquanto que para o $N$. viridula os danos foram verificados na terceira fase, independente da densidade (1 ou 2 percevejos). 
Tabela 3. Efeito de Nezara viridula e Piezodorus guildinii em 3 fases de desenvolvimento das maçãs no peso de capulho. Piracicaba, SP, 2002

\begin{tabular}{lcccc}
\hline \multicolumn{1}{c}{ Espécie } & \multicolumn{2}{c}{ Fases de desenvolvimento das maçãs } & \multirow{2}{*}{$\mathbf{1}^{\mathbf{a}}$} \\
& $5,2 \mathrm{aA}$ & $5,2 \mathrm{aA}$ & $5,2 \mathrm{aA}$ & $5,2 \mathrm{a}$ \\
\hline Testemunha & $5,1 \mathrm{aA}$ & $5,0 \mathrm{aA}$ & $4,9 \mathrm{bB}$ & $5,0 \mathrm{a}$ \\
Nezara viridula & $4,6 \mathrm{bB}$ & $4,7 \mathrm{bB}$ & $5,2 \mathrm{aA}$ & $4,8 \mathrm{~b}$ \\
Piezodorus guildinii & $\mathbf{5 , 0 A}$ & $\mathbf{5 , 0 A}$ & $\mathbf{5 , 1 A}$ & $\mathbf{5 , 0}$ \\
\hline
\end{tabular}

Médias seguidas por letras distintas, minúsculas na coluna e maiúsculas na linha, diferem entre si pelo teste de Tukey $(\mathrm{P} \leq 0,05)$.

Em relação ao peso de 100 sementes, as diferenças ocorreram nas fases de desenvolvimento das maçãs, onde para o percevejo P. guildinii, os danos maiores foram causados na primeira fase e para $N$. viridula o efeito negativo ocorreu próximo à abertura dos capulhos (Tabela 4), não havendo influência da densidade.

Tabela 4. Efeito de Nezara viridula e Piezodorus guildinii em 3 fases de desenvolvimento das maçãs no peso de 100 sementes. Piracicaba, SP, 2002

\begin{tabular}{lcccc}
\hline \multicolumn{1}{c}{ Espécie } & \multicolumn{2}{c}{ Fases de desenvolvimento das maçãs } & \multirow{2}{*}{ Média } \\
& $\mathbf{1}^{\mathbf{a}}$ & $\mathbf{2}^{\underline{\mathbf{a}}}$ & $\mathbf{3}^{\mathbf{a}}$ & \\
\hline Testemunha & $11,2 \mathrm{aA}$ & $12,0 \mathrm{aA}$ & $12,0 \mathrm{aA}$ & $11,7 \mathrm{a}$ \\
Nezara viridula & $11,6 \mathrm{aA}$ & $11,2 \mathrm{aA}$ & $10,9 \mathrm{bB}$ & $11,2 \mathrm{a}$ \\
Piezodorus guildinii & $11,0 \mathrm{aB}$ & $11,7 \mathrm{aA}$ & $11,9 \mathrm{aA}$ & $11,5 \mathrm{a}$ \\
Média & $\mathbf{1 1 , 3 A}$ & $\mathbf{1 1 , 6 A}$ & $\mathbf{1 1 , 6 A}$ & $\mathbf{1 1 , 5}$ \\
\hline
\end{tabular}

Médias seguidas por letras distintas, minúsculas na coluna e maiúsculas na linha, diferem entre si pelo teste de Tukey $(\mathrm{P} \leq 0,05)$.

Como um último fator de análise nos componentes de produção (porcentagem de fibra), a Tabela 5 indica que, a presença de apenas 1 percevejo é o suficiente para causar algum tipo de dano com conseqüente redução da porcentagem de fibra e quando 
comparado entre as espécies (Tabela 6), o $N$. viridula causa uma redução maior (38,8\%) que $P$. guildinii $(39,6 \%)$.

Tabela 5. Efeito da densidade de infestação de Nezara viridula e Piezodorus guildinii na porcentagem de fibra. Piracicaba, SP, 2002

\begin{tabular}{cc}
\hline Densidade de infestação $^{\mathbf{1}}$ & Média \\
\hline 0 & $39,8 \mathrm{a}$ \\
1 & $38,6 \mathrm{~b}$ \\
2 & $39,2 \mathrm{ab}$ \\
Média & 39,2 \\
\hline
\end{tabular}

${ }^{1}$ número de percevejos por maçã de algodoeiro;

Médias seguidas por letras distintas diferem entre si pelo teste de Tukey ( $\mathrm{P} \leq 0,05)$.

Tabela 6. Efeito do ataque de Nezara viridula e Piezodorus guildinii na porcentagem de fibra. Piracicaba, SP, 2002

\begin{tabular}{lc}
\hline \multicolumn{1}{c}{ Espécie } & Média \\
\hline Testemunha & $39,8 \mathrm{a}$ \\
Nezara viridula & $38,8 \mathrm{~b}$ \\
Piezodorus guildinii & $39,6 \mathrm{a}$ \\
Média & 39,2 \\
\hline Médias seguidas por letras distintas diferem entre si pelo teste de Tukey $(\mathrm{P}<0,05)$.
\end{tabular}

Médias seguidas por letras distintas diferem entre si pelo teste de Tukey $(\mathrm{P} \leq 0,05)$. 


\subsubsection{Efeito das espécies e da densidade de infestação nas características tecnológicas da fibra e do fio}

Algumas características tecnológicas analisadas como comprimento de fibra e índice de fibras curtas, tiveram influência direta da espécie e da densidade de percevejos nas fases de desenvolvimento das maçãs.

O comprimento da fibra é uma importante característica pois afeta a resistência e a uniformidade do fio, bem como a eficiência no processo de fiação, pois no processo de torção, as fibras longas tendem a resistir melhor à ruptura (BM\&F, 1993).

Observa-se na Tabela 7, que ocorreu pouca ou quase nenhuma influência de $N$. viridula mesmo com 2 percevejos por maçã nas três fases de desenvolvimento das maçãs. Entretanto a Tabela 8 evidencia a influência negativa de P. guildinii com relação ao comprimento da fibra, destacando-se o efeito na terceira fase.

Tabela 7. Danos causados ao comprimento da fibra (mm) de algodão em três densidades de infestação de Nezara viridula e em 3 fases de desenvolvimento das maçãs. Piracicaba, SP, 2002

\begin{tabular}{|c|c|c|c|c|}
\hline \multirow{2}{*}{$\begin{array}{c}\text { Densidade de } \\
\text { infestação }\end{array}$} & \multicolumn{3}{|c|}{ Fases de desenvolvimento das maçãs } & \multirow{2}{*}{ Média } \\
\hline & $1^{\mathbf{a}}$ & $2^{\mathbf{a}}$ & $3^{\mathbf{a}}$ & \\
\hline 0 & $29,0 \mathrm{aA}$ & 28,8 aA & $29,3 \mathrm{aA}$ & $29,0 \mathrm{a}$ \\
\hline 1 & 28,5 aAB & 29,3 aA & $27,8 \mathrm{bB}$ & 28,5 a \\
\hline 2 & 28,6 aA & 28,8 aA & $28,3 \mathrm{abA}$ & 28,6 a \\
\hline Média & 28,7 A & 28,9 A & 28,4 A & 28,7 \\
\hline
\end{tabular}


Tabela 8. Danos causados ao comprimento da fibra (mm) de algodão em três densidades de infestação de Piezodorus guildinii em 3 fases de desenvolvimento das maçãs. Piracicaba, SP, 2002

\begin{tabular}{|c|c|c|c|c|}
\hline \multirow{2}{*}{$\begin{array}{c}\text { Densidade de } \\
\text { infestação }^{1}\end{array}$} & \multicolumn{3}{|c|}{ Fases de desenvolvimento das maçãs } & \multirow{2}{*}{ Média } \\
\hline & $\mathbf{1}^{\mathrm{a}}$ & $2^{\underline{a}}$ & $3^{\underline{a}}$ & \\
\hline 0 & $29,2 \mathrm{aA}$ & 28,8 aA & 29,3 aA & $29,0 \mathrm{a}$ \\
\hline 1 & 28,2 aA & 28,6 aA & 28,0 bA & $28,3 \mathrm{~b}$ \\
\hline 2 & 28,8 aA & 28,8 aA & 27,7 bB & $28,4 \mathrm{~b}$ \\
\hline Média & 28,7 a & 28,7 A & 28,3 A & 28,6 \\
\hline
\end{tabular}

${ }^{1}$ número de percevejos por maçã de algodoeiro;

Médias seguidas por letras distintas, minúsculas na coluna e maiúsculas na linha, diferem entre si pelo teste de Tukey $(\mathrm{P} \leq 0,05)$.

Em relação ao índice de fibras curtas, nota-se um ligeiro aumento na porcentagem destas fibras principalmente na terceira fase (Figuras 5 e 6) tanto para $P$. guildinii como para $N$. viridula, o que segundo a BM\&F (1993), poderiam ocasionar rupturas das fibras e do fio, por resistir pouco ao processo de torção e estiramento na fiação.

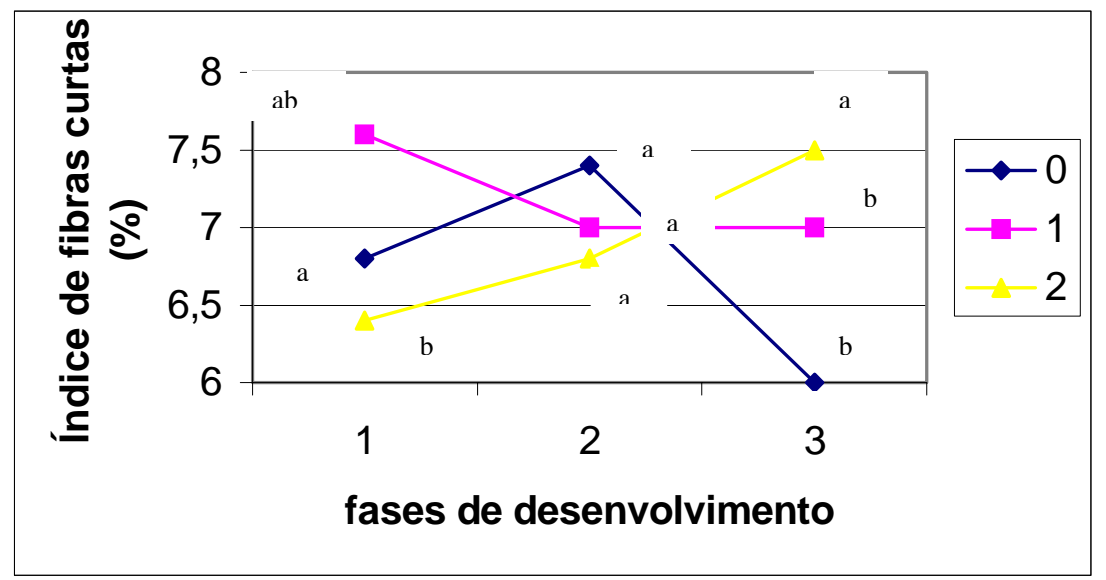

Figura 5- Índice de fibras curtas (\%) em três densidades de infestação de $P$. guildinii em 3 fases de desenvolvimento das maçãs. Piracicaba, SP, 2002 


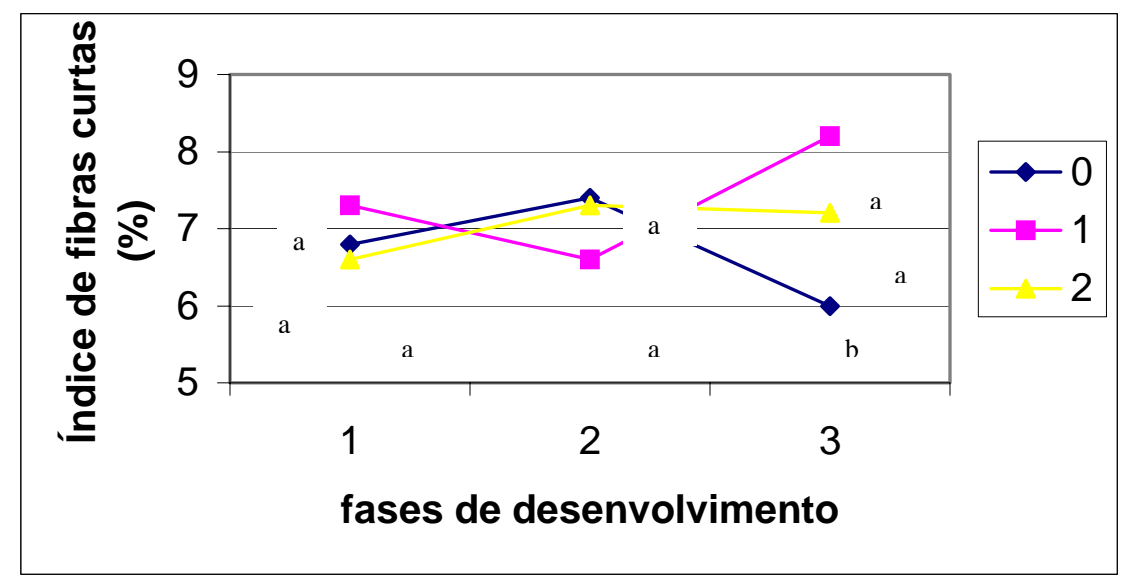

Figura 6- Índice de fibras curtas (\%) em três densidades de infestação de $N$. viridula em 3 fases de desenvolvimento das maçãs. Piracicaba, SP, 2002

Médias seguidas por letras distintas diferem entre si pelo teste de Tukey $(\mathrm{P} \leq 0,05)$.

Nas demais características tecnológicas analisadas pelo teste HVI, não ocorreram diferenças significativas entre as fases de desenvolvimento das maçãs e entre as espécies de percevejos. Porém, a densidade de infestação ou seja, tanto 1 como 2 percevejos independente da espécie, causaram diferenças estatísticas significativas na maioria das características analisadas, em relação à testemunha (Tabela 9).

A uniformidade do comprimento afeta a resistência, a finura da fibra e a eficiência do processo de fiação, sendo também relacionada ao conteúdo de fibras curtas (BM\&F, 1993). Assim, apesar de uma ligeira tendência no aumento do índice de fibras curtas em virtude da ação dos percevejos no período antecedente à abertura dos capulhos, verificado nos gráficos anteriores, a densidade de infestação não ocasionou diferenças significativas na média das três fases de desenvolvimento na uniformidade do comprimento.

Com relação à finura da fibra, o efeito da ação dos percevejos evidenciou uma tendência de queda nos valores da testemunha, proporcionando fibras mais finas, o que segundo a BM\&F (1993) influenciam diretamente na formação de "neps” (pequenos nós constituídos por fibras mortas), dificultando seu processo industrial. 
A porcentagem de reflectância da fibra foi alterada de modo inverso com a ação dos percevejos alterando para maior os valores.

Em relação à tenacidade de ruptura e à maturidade, ambas estão relacionadas com a resistência do fio. Verifica-se que houve uma diminuição dos valores na presença dos percevejos, ou seja, as fibras tendem a se tornar menos resistente como resultado de uma deposição irregular das camadas de celulose na parede secundária da fibra (Fundação MT, 2001). Esta tendência se revela também no índice micronaire , que corresponde à finura e ao grau de maturidade ao mesmo tempo, onde fibras imaturas se comportam como fibras finas, e os resultados atenuam para uma diminuição no seu índice devido ao aumento destas fibras (BM\&F, 1993).

Tabela 9. Influência da densidade de infestação de Nezara viridula e Piezodorus guildinii nas características tecnológicas da fibra. Piracicaba, SP, 2002

\begin{tabular}{|c|c|c|c|}
\hline \multirow{2}{*}{ Características da fibra } & \multicolumn{3}{|c|}{ Densidade de infestação (nº) } \\
\hline & $\mathbf{0}$ & 1 & 2 \\
\hline Uniformidade do comp. da fibra (\%) & 45,3 a & $45,8 \mathrm{a}$ & $46,0 \mathrm{a}$ \\
\hline Finura da fibra (m/Tex) & 225,0 a & $197,0 \quad b$ & 202,4 b \\
\hline Reflectância da fibra (\%) & $74,5 \mathrm{a}$ & $76,0 \quad b$ & $76,1 \mathrm{~b}$ \\
\hline Micronaire & $4,9 \mathrm{a}$ & $4,3 \mathrm{~b}$ & $4,4 \mathrm{~b}$ \\
\hline Tenacidade de ruptura da fibra (g/Tex) & 32,9 a & $30,3 \mathrm{~b}$ & $30,5 \mathrm{~b}$ \\
\hline Maturidade (\%) & 78,5 a & $75,2 \mathrm{~b}$ & $75,7 \mathrm{~b}$ \\
\hline
\end{tabular}

Médias seguidas por letras distintas na linha, diferem entre si pelo teste de Tukey $(\mathrm{P} \leq 0,05)$. 


\section{CONCLUSÕES}

- Os sintomas externos começam com pontuações pretas, evoluindo para formação de calosidades internas, ocasionando a queda, ou afetando internamente as fibras, ocasionando a abertura precoce das maçãs, causando conseqüente redução na produção;

- Em maçãs com até 10 dias de idade, a porcentagem de queda foi bastante significativa, tanto para $N$. viridula como para $P$. guildinii, tendo correlação significativa entre quantidade de percevejos e queda de maçãs, sendo que na medida em que a maçã se desenvolve, ocorre diminuição na porcentagem de queda;

- Com relação às características componentes de produção, verificou-se que a densidade de infestação não foi fator importante e que $P$. guildinii causou maiores danos até os vinte dias tanto para peso de um capulho como para peso de cem sementes, sendo que os danos de $N$. viridula ocorreram próximo à abertura dos capulhos, e para porcentagem de fibra $N$. viridula foi mais prejudicial;

- Com relação às características tecnológicas das fibras e do fio, novamente a densidade de infestação não teve influência sobre os níveis de danos e de uma forma geral, tanto $P$. guildinii como $N$. viridula causaram danos significativos na maioria das características analisadas, exceção feita a reflectância onde ocorreu ação inversa. 


\section{REFERÊNCIAS BIBLIOGRÁFICAS}

ARANTES, N. E.; PENNA, V. C. J.; SILVA, C. M. Algodão e soja: guia técnico de campo. Belo Horizonte: APSEMG, 1998. 174 p.

BARROS, M. A. L.; SANTOS, R. F.; CAVALCANTE, J. J. Evolução da cotonicultura na década de 1980. In: REUNIÃO NACIONAL DO ALGODÃO, 6., Campina Grande, 1990. Resumos. Campina Grande: Embrapa Algodão, 1990. p.68.

BELTRÃO, N. E. M. Algodão brasileiro em relação ao mundo: situação e perspectivas. In: BELTRÃO, N. E. M. (Org.). O agronegócio do algodão no Brasil. Brasília: Embrapa Algodão, 1999. cap.1, p.15-27.

BENEDICT, C. R. Physiology. In: KOHEL, R. J.; LEWIS, C. F. (Ed.). Cotton. Madison: ASA; CSSA; SSSA, 1984. p.151-200.

BERGER, P. G.; PICANÇO, M. C.; LAVANDIR, J.; ZAMBOLIM, L.; FERNANDES, F. L. Fatores associados à mancha da maçã do algodão. In: CONGRESSO BRASILEIRO DE ALGODÃO, 3., Campo Grande, 2001. Anais. Campo Grande: EMBRAPA/UFMS, 2001. p.298-299.

BUNDY, C. S.; McPHERSON, R. M. Dynamics and seasonal abundance of stink bugs (Heteroptera: Pentatomidae) in a cotton-soybean ecosistem. Journal of Economic Entomology, v.93, n.3, p. 697-706, 2000.

CORPUZ, L. R. The biology, host range and natural enemies of Nezara viridula L. (Pentatomidae: Hemiptera). Philippine Entomologist, v.1, n.3, p.225-239, 1969. 
CORRÊA-FERREIRA, B. S. Criação massal do percevejo verde Nezara viridula (L.). Londrina: Embrapa, CNPSo, 1985. 16p. (EMBRAPA. CNPSo. Documento, $11)$.

CORRÊA-FERREIRA, B. S. Utilização do parasitóide de ovos Trissolcus basalis (Wollaston) no controle de percevejos da soja, Londrina: EMBRAPA, CNPSo, 1993. 40p. (Embrapa. CNPSo. Circular Técnica, 11).

CORSEUIL, E.; CRUZ, F. Z.; MEYER, L. M. C. Insetos nocivos à soja no Rio Grande do Sul. Porto Alegre: UFRGS, 1974. 36p.

COSTA, E.C.; LINK, D. Incidência de percevejos em soja. Revista do Centro de Ciências Rurais, v.4, n.4, p.397-400, 1974.

COSTA, M. M. L. Técnicas de criação de Nezara viridula (L., 1758) (Hemiptera: Pentatomidae) e sua relação com o parasitóide Eutrichopodopsis nitens Blanchard, 1966 (Diptera: Tachinidae). Piracicaba, 1991. 134p. Dissertação (Mestrado) Escola Superior de Agricultura “Luiz de Queiroz”, Universidade de São Paulo. .

COSTA, M. T. P. M.; OLIVEIRA, A. C. S. Aspectos econômicos da cultura do algodão. Informe Agropecuário, v.8, n. 92, p.3-7, 1982.

DEWITT, N. B.; GODFREY, G.L. The literature of arthropods associated with soybeans II: a bibliography of the southern stink bug Nezara viridula (Linnaeus). Urbana: Departament of Registration and Education/Natural History Survey Division, 1972. 23p (Biological Notes, 78).

DUNCAN , R. G.; WALKER, J. R. Some effects of the southern green stink bug on soybeans. La Agriculture, v.12, n.2, p.10-11, 1968. 
FERREIRA, B. S. C.; PANIZZI, A. R. Percevejos-pragas da soja no norte do Paraná: abundância em relação à fenologia da planta e hospedeiros intermediários. In: SEMINÁRIO NACIONAL DE PESQUISA DA SOJA, 2., Londrina, 1982. Anais. Londrina: EMBRAPA, CNPSo, 1982. p. 140-151.

FNP CONSULTORIA \& COMÉRCIO. Agrianual 2002: anuário estatístico da agricultura brasileira. São Paulo, 2002. p.141-142: Algodão.

FNP CONSULTORIA \& COMÉRCIO. Agrianual 2003: anuário estatístico da agricultura brasileira. São Paulo, 2003. p.206: Algodão.

FRYXELL, P. A. Taxonomy and germoplasm resources. In: KOHEL, R. J.;LEWIS, C. F. (Ed.). Cotton. Madison: ASA; CSSA; SSSA; 1984. cap.2, p.27-57.

FUNDAÇÃO MT. Boletim de pesquisa de algodão. Rondonópolis: Fundação MT. 2001. 238 p. (Boletim 4).

FUZZATO, M. G. Melhoramento genético do algodoeiro. In: CIA, E.; FREIRE, E. C.; SANTOS, W. J. (Ed.). Cultura do Algodoeiro. Piracicaba: POTAFOS, 1999. p.15-34.

GALLO, D.; NAKANO, O.; SILVEIRA NETO, S.; CARVALHO, R. P. L.; BAPTISTA, G. C. de; BERTI FILHO, E.; PARRA, J. R. P.; ZUCCHI, R. A.; ALVES. S. B.; VENDRAMIN, J. D.; MARCHINI, L. C.; LOPES, J. R. S.; OMOTO, C. Entomologia agrícola. Piracicaba: FEALQ, 2002. 920p.

GONÇALVES, J. S. Proposta de diretrizes básicas para a intervenção governamental no desenvolvimento do complexo têxtil brasileiro. Informações Econômicas, v.24, n.4, p.9-26, 1994.

GRAZIA, J. Revisão dos pentatomídeos citados no "Quarto Catálogo dos insetos que vivem nas plantas do Brasil" (Hemiptera: Pentatomidae). Dusenia, v.10, n.3, p.161174, 1977. 
GREENE, J. K.; TURNIPSEED, S. G.; SULLIVAN, M. J. Treatment thresholds for stink bugs (Hemiptera: Heteroptera) in cotton. Journal of Economic Entomology, v.94, n.2, p.403-409, 2001.

GREENE, J. K.; TURNIPSEED, S. G.; SUlliVAN, M. J.; HERZOG, G. A. Boll damage by southern green stink bug (Hemiptera: Pentatomidae) and tarnished plant bug (Hemiptera: Miridae) caged on transgenic Bacillus thuringiensis cotton. Journal of Economic Entomology, v.92, n.4, p.941-944, 1999.

GRIDI-PAPP, I. L. Botânica e genética. In: NEVES, O. S. (Ed.). Cultura e adubação do algodoeiro. São Paulo: Instituto Brasileiro de Potassa, 1965. p. 117-160.

HARRIS, V. E.; TODD. J. W. Rearing the southern green stink bug, Nezara viridula, with relevant aspects of its biology. Journal of the Georgia Entomological Society, v.16, n. 2, p.203-210, 1981.

HARRIS, V. E.; TODD, J. W.; MULLINIX, B. G. Color change as an indicator of adult diapause in the southern green stink bug Nezara viridula. Journal of Agriculture Entomological, v.1, p.82-91, 1984.

HOKKANEN, H. Polymorphism, parasites, and the native area of Nezara viridula (Hemiptera: Pentatomidae). Annales Entomologici Fennici, v. 52, p.28-31, 1986.

JONES, W. A. Nezara viridula. In: SINGH, P.; MOORE, R. F. (Ed.). Handbook of insect rearing. Amsterdam: Elsevier Science, 1985. cap.1, p.339-343.

KERBY , T. A.; KELLEY, M. Growth and development of acala cotton. Berkeley: University of California, Agricultural Experiment Station, 1987. (Bulletin, 1921).

KERBY , T. A.; HAKE, K. Monitoring cotton's growth. In: KERBY, T. A.; HAKE, K.; HAKE, S. (Ed.). Cotton production manual. Oakland: ANR Publications, 1993. 417p.

KIRITANI, K. Natural control of populations of the southern green stink bug, Nezara viridula. Researches Population Ecology, v.6, p.88-98, 1964. 
KIRITANI, K.; HOKYO, N. Studies on the life table of the southern green stink bug, Nezara viridula. Japanese Journal of Applied Entomology, v.6, p.124-139, 1962.

KIRITANI, K.; KIMURA, K. The effect of population density during nymphal and adult stages on the fecundity and other reproductive performances. Japanese Journal Ecology, v.15, p.233-236, 1965.

KIRITANI, K.; HOKYO, N.; KIMURA, K. Factors affecting the winter mortality in the southern green stink bug, Nezara viridula L. Annales de la Societe Entomologique de France, v.2, p.199-207, 1966.

LETHIERRY, L.; SEVERIN, G. Catalogue general des Hemipteres, F. Hayez. Bruxelas: Academic Royal Belg., 1893. v. 1. Hétéroptéres Pentatomidae. 286p.

McPHERSON, R. M.; NEWSOM, L. D.; FARTHING, B. F. Evaluation of four stink bug species from three general affecting soybean yield and quality in Louisiana. Journal of Economic Entomology, v.72, p.188-194, 1979.

MARUR , C. J.; RUANO, O. Escala do algodão. Revista Cultivar, v.4, n.38, p. 16-17, 2002.

MAUNEY, J. R. Anatomy and morphology of cultivated cottons. In: KOHEL, R. J.; LEWIS, C. F. (Ed.). Cotton. Madison: ASA; CSSA; SSSA, 1984. p. 59-80.

MITCHELL, W. C.; MAU, R .F. L. Response of the female southern green stink bug and its parasite, Trichopoda pennipes, to male stink bug pheromones. Journal of Economic Entomology, v.64, n.4, p.856-859, 1971.

MORAES, N. C. Competitividade do algodão brasileiro no mercado internacional e implicações da integração ao Mercosul. Viçosa, 1997. 68p. Dissertação (Mestrado)-Universidade Federal de Viçosa. 
NAKANO, O; SILVEIRA NETO, S.; ZUCCHI, R. A. Entomologia econômica. 2.ed. Piracicaba: Esalq, 1981. 314 p.

PANIZZI, A. R. Biologia e danos causados à soja por Piezodorus guildinii (Westwood, 1837) (Hemiptera: Pentatomidae). Curitiba, 1975. 129p. Dissertação (Mestrado) Universidade Federal do Paraná.

PANIZZI, A. R.; SMITH, J. G. Biology of Piezodorus guildinii: oviposition, development time, adult sex ratio, and longevity. Annais Entomological Society American, v.70, n.1, p.35-39, 1977.

PANIZZI, A. R.; SLANSKY JUNIOR, F. Review of phytophagous pentatomids (Hemiptera: Pentatomidae) associated with soybean in the Americas. Florida Entomologist, v.68, n.1, p.184-214, 1985.

PANIZZI, A. R.; PARRA, J. R. P.; SANTOS, C. H.; CARVALHO, D. R. Rearing the southern green stink bug using an artificial dry diet and an artificial plant. Pesquisa Agropecuária Brasileira, v. 35, n.9, p.1709-1715, 2000.

PANIZZI, A. R.; GALILEO, M. H. M.; GASTAL, H. A. O.; TOLEDO, J. F. F.; WILD, C. H. Dispersal of Nezara viridula and Piezodorus guildinii nymphs in soybeans. Environmental Entomology, v.9, n.3, p.293-297, 1980.

PASSOS, S. M. G. Algodão. Campinas: Instituto Campineiro de Ensino Agrícola, 1982. 424p.

POPICH, S. B.; VIDELA, G. W. Hemipteros fitófagos observados en cultivos de algodón en la Republica Argentina (Campaña 2000-2001). In: CONGRESSO BRASILEIRO DE ALGODÃO, 3., Campo Grande, 2001. Anais. Campo Grande: EMBRAPA/ UFMS, 2001. p.300-302.

RESENDE, L. M. A.; MOURA, P. A. M. Aspectos econômicos da cultura do algodoeiro. Informe Agropecuário, v.15, n.166, p.5-12, 1990. 
RIBEIRO, J. S. F.; BACCHI, L. M. A.; DEGRANDE, P. E. Apodrecimento prematuro. Revista Cultivar, v.2, n.19, p. 8-9, 2000.

RIBEIRO, J. S. F.; RIBEIRO, J. F.; BARROS, R.; OLIVEIRA, M.; BARROS, R.; NOGUEIRA, R. DEGRANDE, P. E. Danos de percevejos causadores de podridões de maçãs em variedades de algodoeiros. In: CONGRESSO BRASILEIRO DE ALGODÃO, 3., Campo Grande, 2001. Anais. Campo Grande: EMBRAPA/ UFMS, 2001. p.186-187.

RIZZO, H. F. E. Aspectos morfológicos e biológicos de Nezara viridula (L.) (Hemiptera: Pentatomidae). Agronomia Tropical, v.18, n.2, p.249-274, 1968.

ROSOLEM, A. C. Ecofisiologia e manejo da cultura do algodoeiro. Informações Agronômicas, n.95, p.1-9, set. 2001.

SANTOS, C. M. Influência do controle do crescimento, do uso de fungicidas e da freqüência de colheita, nos caracteres agronômicos e na qualidade da fibra e da semente do algodoeiro (Gossypium hirsutum L.). Viçosa, 1993. 184p. Tese (Doutorado) - Universidade Federal de Viçosa.

SANTOS, W. J. Monitoramento e controle de pragas do algodoeiro. In: CIA, E.; FREIRE, E.C.; SANTOS, W.J. (Ed.). Cultura do algodoeiro. Piracicaba: POTAFOS, 1999. p. 133-179.

TODD, J. W. Ecology and behaviour of Nezara viridula. Annual Review of Entomology, v.34, p.273-292, 1989.

TODD. J. W.; TURNIPSEED, S. G. Effects of southern green stink bug damage on yeld and quality of soybean. Journal of Economic Entomology, v.67, n.3, p.421-426, 1974.

WALDBAUER, G. P. Damage to soybean seeds by south american stink bugs. Anais da Sociedade Entomológica do Brasil, v.6, n.2, p.224-229, 1977. 
YERGAN, K. V. Effects of green stink bug damage on yield and quality of soybeans. Journal of Economic Entomology, v.70, p.619-622, 1977.

YUKAWA, J.; KIRITANI, K. Polimorphism in the southern green stink bug. Pacific Insects, v.7, n.4, p.639-642, 1965. 